\title{
MINERAL WATERS STUDY WITH HELP OF ADMITTANCE SPECTROSCOPY
}

\author{
Yevgen Pokhodylo, Dr.Sc., Prof.: e-mail: evgenp@meta.ua Volodymyr Boyko, master, \\ Lviv Polytechnic National University, Ukraine
}

\begin{abstract}
The paper proposes a method of identification of mineral waters by components of their immittance. The active and reactive components of the admittances are selected as such components. We received the results of experimental researches on components of admittance of mineral waters of different types in the frequency range of the test signal. Experimental researches were performed on real samples of mineral waters. Analysis of the results showed the following. Among all types of samples, Polyana Kvasova water differs significantly in electrical parameters. It differs from all by the form of the curve (the dependence of the components on the frequency) and much higher absolute values of the components of the admittance. Identification of mineral waters is carried out by comparing the components of the test sample with the corresponding components of the reference sample. This allows you to quickly detect falsification of mineral water. Such identification can be implemented by one measuring instrument and by the same method.
\end{abstract}

Keywords

Admittance, Reactive component of admittance, Active component of admittance, Mineral water, Product identification, Standard sample, Impedance spectroscopy.

\section{Introduction}

In recent years, the production of mineral waters has moved from enterprises with a well-established technological cycle, strict control, and qualified personnel to small enterprises [1]. With the change in water production technology, a significant amount of counterfeit and little-studied imported mineral bottled water appears on the market. The reasons for the falsification of bottled mineral waters in Ukraine are a much higher price compared to tap water. Therefore, there was a problem with ensuring their identification. The main criterion for the identification of mineral waters by the consumer is the indicators printed on the label. However, they very often do not correspond to real indicators. Traditional physicochemical methods and tools are designed to work in the laboratory. Mostly they are designed to control individual quality indicators. In many cases, methods and tools are needed to work in the field. Therefore, to detect counterfeiting under such conditions requires a rapid method of analysis. This can be ensured by choosing the identification mark of mineral water. This may be the admittance of water [2-5], that is admittance components at fixed frequencies. In this case, with the help of a capacitive sensor, water is supplied as the admittance of the multi-element bipolar. The components of such a bipolar characterize the properties of mineral water.

\section{Disadvantages}

The analysis of known instrumental methods of the analysis showed that their application concerns the determination of individual components of mineral water. Thus the process of implementing such methods complicates the measuring instrument when determining the few components of mineral water simultaneously.

\section{The Purpose of the Work}

The current work aims to propose a mineral water electrical identification method based on the parameters of complex electrical conductivity (admittance).

\section{Mineral Waters Studies based on Admittance Parameters}

\subsection{The essence of admittance spectroscopy}

To identify mineral water offered use the immittance method of quality control [1]. The immittance method combines impedance and admittance methods. In our case, we used the admittance method of quality control to identify mineral water. The essence of this method is that the samples of mineral water are compared. One of them controlled, and the other - with standard normalized characteristics (standard). If the comparison is carried out by a single parameter, it is often impossible to distinguish quality products from counterfeit. Therefore, the more comparison parameters, the more difficult the measurement, but at the same time falsification is more impossible. These parameters are active and reactive components admittance of water at many frequencies. In this case, the use of electrical methods for identifying products of non-electrical nature makes it possible to "record" the electrical parameters of both controlled and standard samples. They reflect their properties in the form of individual electrical parameters of the admixture of a multi-element bipolar. This approach unifies the quality indicators of controlled and standard samples, appropriate controls, and methods. Therefore, according to the admittance method of identification of any product of an unknown substitution scheme, the relative identification parameters can be represented by the expressions:

$$
\left(\frac{\operatorname{Im}\left(\mathrm{Y}_{\mathrm{x}}\right)}{\operatorname{Im}\left(\mathrm{Y}_{0}\right)}\right)_{\mathrm{f} 1}=\mathrm{b}_{1},\left(\frac{\operatorname{Im}\left(\mathrm{Y}_{\mathrm{x}}\right)}{\operatorname{Im}\left(\mathrm{Y}_{0}\right)}\right)_{\mathrm{f} 2}=\mathrm{b}_{2},\left(\frac{\operatorname{Im}\left(\mathrm{Y}_{\mathrm{x}}\right)}{\operatorname{Im}\left(\mathrm{Y}_{0}\right)}\right)_{\mathrm{f} 3}=\mathrm{b}_{3}, \ldots,\left(\frac{\operatorname{Im}\left(\mathrm{Y}_{\mathrm{x}}\right)}{\operatorname{Im}\left(\mathrm{Y}_{0}\right)}\right)_{\mathrm{fn}}=b_{\mathrm{n}},
$$




$$
\left(\frac{\operatorname{Re}\left(\mathrm{Y}_{\mathrm{x}}\right)}{\operatorname{Re}\left(\mathrm{Y}_{0}\right)}\right)_{\mathrm{f} 1}=\mathrm{g}_{1},\left(\frac{\operatorname{Re}\left(\mathrm{Y}_{\mathrm{x}}\right)}{\operatorname{Re}\left(\mathrm{Y}_{0}\right)}\right)_{\mathrm{f} 2}=\mathrm{g}_{2},\left(\frac{\operatorname{Re}\left(\mathrm{Y}_{\mathrm{x}}\right)}{\operatorname{Re}\left(\mathrm{Y}_{0}\right)}\right)_{\mathrm{f} 3}=\mathrm{g}_{3}, \ldots,\left(\frac{\operatorname{Re}\left(\mathrm{Y}_{\mathrm{x}}\right)}{\operatorname{Re}\left(\mathrm{Y}_{0}\right)}\right)_{\mathrm{f} 1}=\mathrm{g}_{\mathrm{n}},
$$

where $Y_{x}, Y_{0}$ are the research object and the standard sample accordingly; $\operatorname{Im}\left(\mathrm{Y}_{\mathrm{x}}\right), \operatorname{Re}\left(\mathrm{Y}_{\mathrm{x}}\right), \operatorname{Im}\left(\mathrm{Y}_{0}\right)$, $\operatorname{Re}\left(\mathrm{Y}_{0}\right)$ are the reactive and active components of the test object and the standard sample; $f_{1}, f_{2}, f_{3}, \ldots, f_{n}$ are the frequencies at which the components are measured; $b_{1}, b_{2}, b_{3}, \ldots, b_{n}$ are the ratio of reactive components; $g_{1}$, $\mathrm{g}_{2}, \mathrm{~g}_{3}, \ldots, \mathrm{g}_{\mathrm{n}}$ are the ratio of active ingredients.

\subsection{Implementation of mineral water identification}

Based on this, you can form the following stages of identification of mineral water.

1) Formation of a traditional standard sample of the object of control in the form of measured electrical parameters (a component of the admission at fixed frequencies).In this way, we obtain an electrical reference for identification.

2) Measurement at the same fixed frequencies following the electrical standard sample of active and reactive components of the admittances of the controlled sample of mineral water,

3) Comparison of electrical parameters of an electrical standard sample and a sample of a controlled object. In this way, the differential method of quality control known in qualimetry is realized.

\subsection{The results of experimental researches}

Experimental researches of mineral waters were carried out using RLC - meter and capacitive sensor of coaxial type. Non-carbonated mineral waters packaged in PET containers were used for the study (FER - polyethylene terephthalate).

Test samples of water are divided into three groups by chemical composition, namely:

- hydrocarbon group («Dobra voda» and «Karpatska dzherelna»);

- sodium bicarbonate group («Polyana kvasova »;

- chloride («Morshynska» «Myrhorodska», «Truskavetska»).

The first stage of the study is a sampling. For this purpose, $50 \mathrm{ml}$ of each mineral water sample was taken. After that, the reactive and active components of the admittances of the test samples were measured at fixed frequencies of the specified range.

\section{- The hydrocarbon group of mineral water studies}

The results of the study of water in the form of a graphical representation of the dependences of the active and reactive components of the admixture on the frequency of the image in Fig.1a and 1b, in accordance.
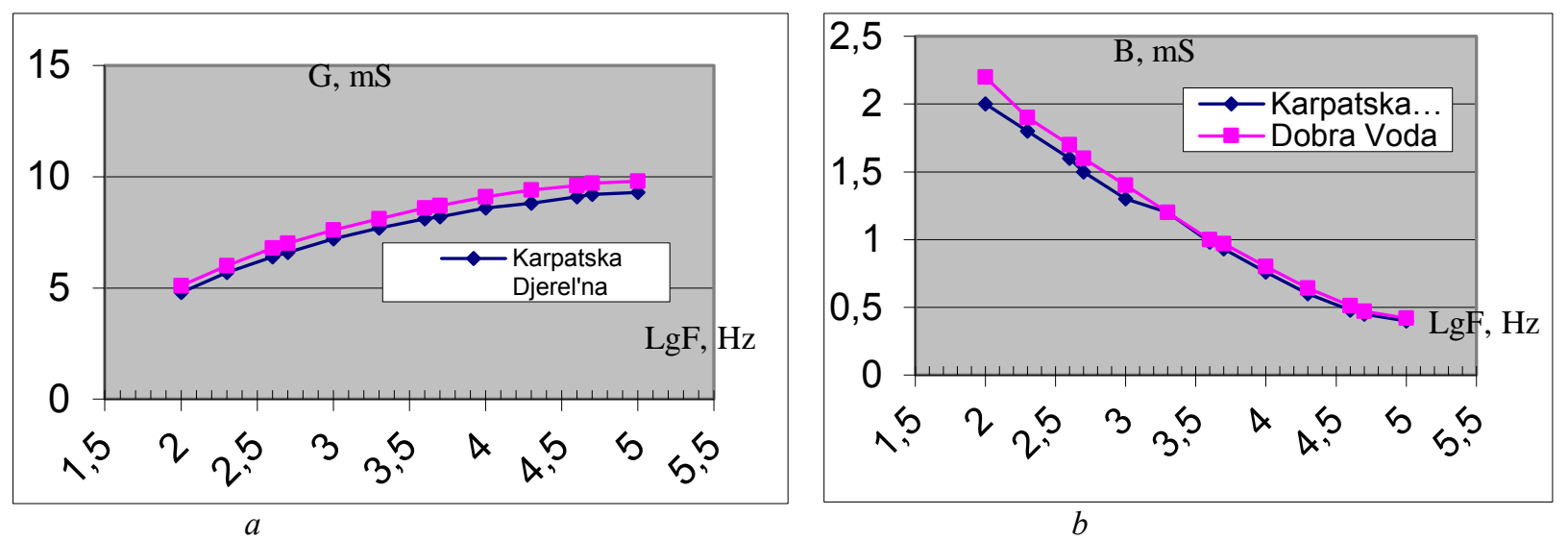

Fig.1. The dependences of active and reactive components of the admixture on the frequency: a) active component; b) reactive components

\section{- Sodium bicarbonate mineral water studies}

The results of the study of sodium bicarbonate water "Polyana kvasova" in the form of a graphical representation of the dependences of the active and reactive components of the admittance on the frequency shown in Fig.2a and $2 b$, in accordance. 

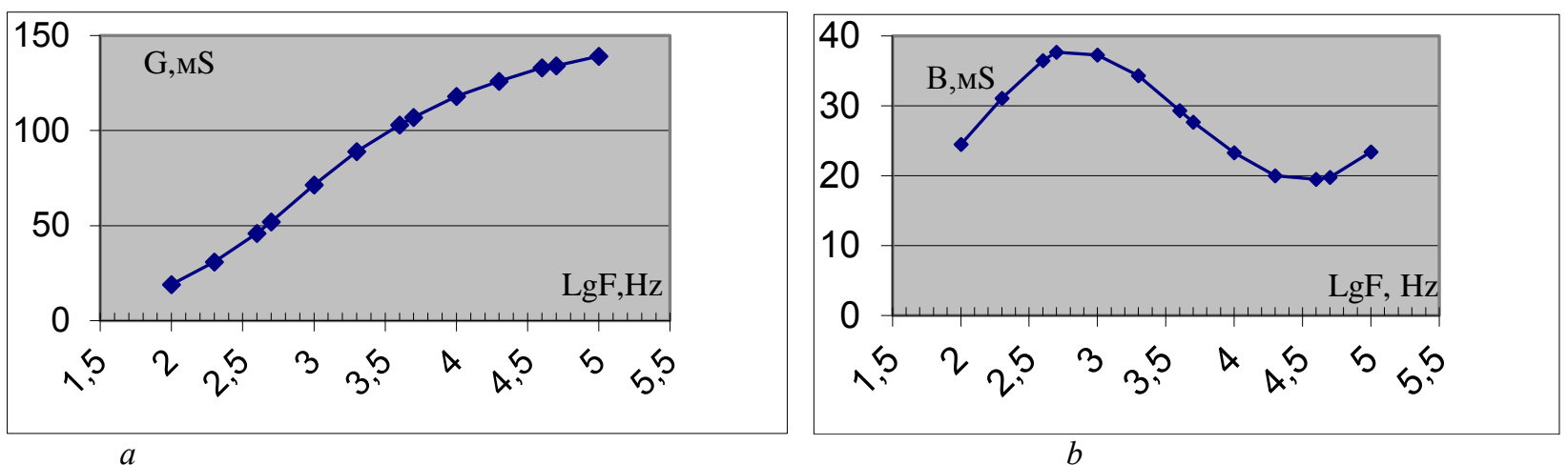

Fig.2. The dependences of admixture active and reactive components of the "Polyana kvasova" water on the frequency: a) active component; b) reactive components

\section{- Chloride group of mineral water studies}

Comparison of the results of the study of three representatives of the chloride group of mineral waters images in Fig.3.
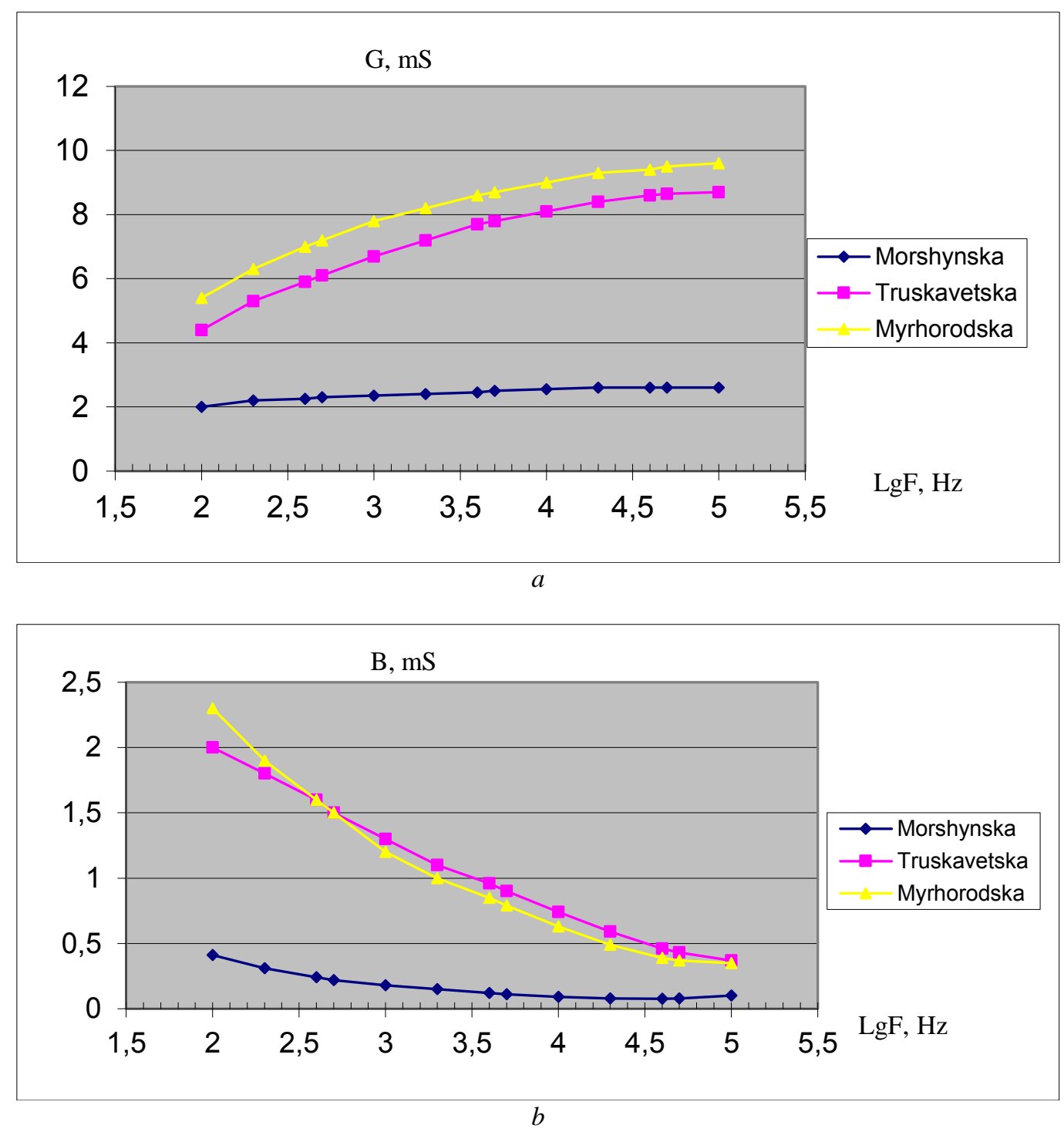

Fig.3. The dependences of admixture reactive components of the chloride group of mineral waters on the frequency

A comparison of the obtained dependences of the admittance components for different mineral waters is given in Fig.4 and Fig.5. 


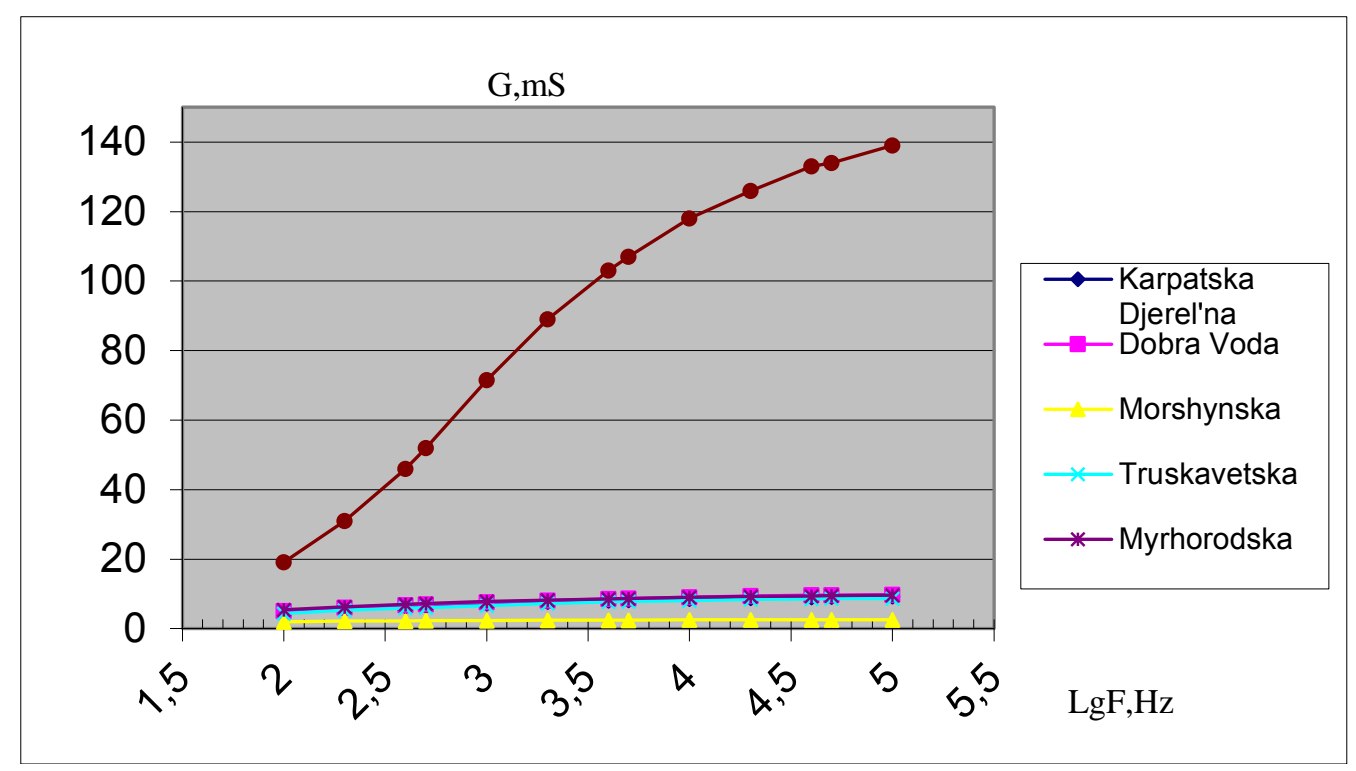

Fig.4. The dependences of admixture active components of the chloride group of mineral waters on the frequency

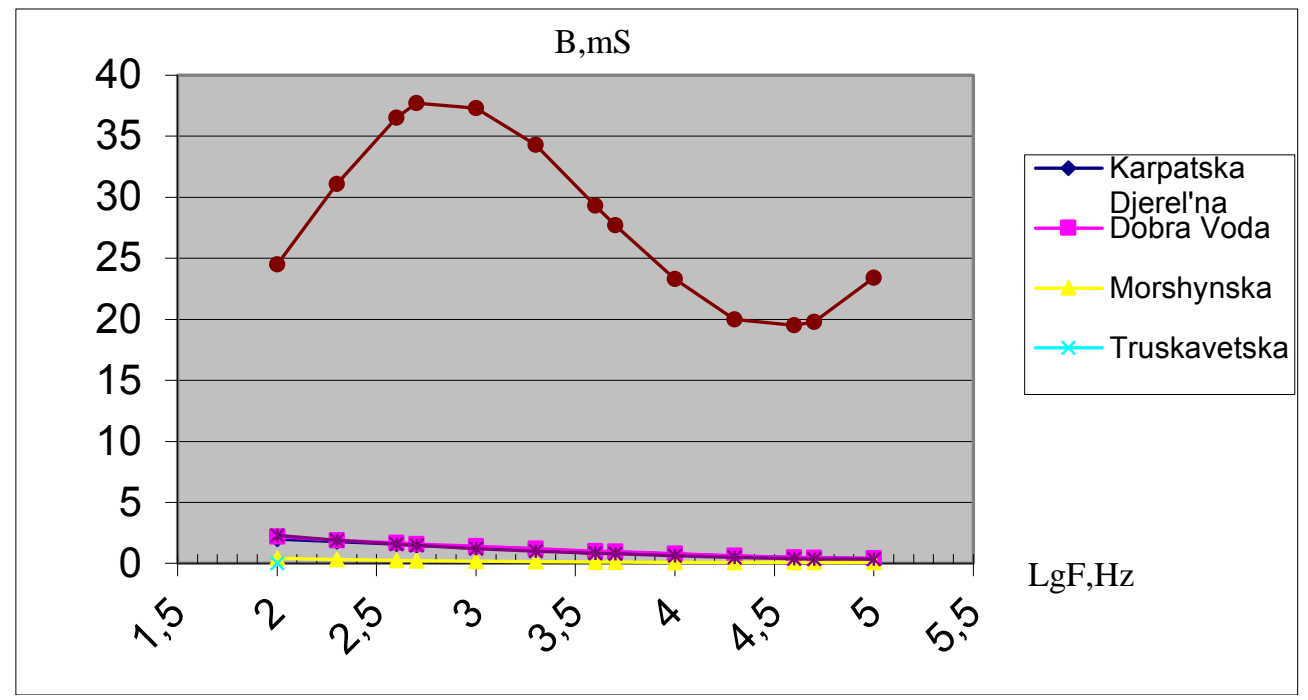

Fig.5. The dependences of admixture reactive components of the chloride group of mineral waters on the frequency

\section{Conclusions}

The analysis of the results of experimental studies has demonstrated the following.

1. Among all types of prototypes, the water "Polyana Kvasova" differs significantly in electrical parameters. It differs by the form of a curve, and by significantly higher absolute values of components of an admittance.

2. The value of conductivity in each group is influenced by the rate of water mineralization: the lower the rate of mineralization, the lower the value of conductivity.

3. The components of the admittance can be used to identify mineral waters and detect their falsification. It is necessary to have electrical standard samples in the form of the results of experimental studies of their components. Standard samples must meet the requirements of the standard. In case of deviations of the values of the components of the controlled and standard samples of mineral water, it is possible to detect non-compliance with the normative parameters.

4. Identification by generalized indicator makes it possible to propose one measuring instrument and one method of identification.

\section{Acknowledgments}

The authors express their gratitude to the staff of the Department of Information-Measuring Technologies of Lviv Polytechnic National University, Ukraine, for the assistance in the preparation of this article. 


\section{Conflict of Interests}

Conflict of interest while writing, preparing, and publishing the article as well as mutual claims by the co-authors is absent.

\section{References}

[1] A. Savon, G. Kousmanov, "Food Quality and Safety Standards at a Glance", Biotechnology \& Biotechnological Equipment, vol.23, no.4, pp.1462-1468, 2014.

[2] Ya. Pushkarova, A. Sledzevskaya, "Panteleimonov et al, Identification of water samples from different springs and rivers of Kharkiv: Comparison of methods for multivariate data analysis", Mosc. Un. Chem. Bull., vol.68, no.1, pp.60-66, 2013.

[3] O. Vasyukov, V. Andronov, V. Loboychenko, "Method of identification of aqueous solution of medium and high mineralization", G 01 N 27/00, G 01 N 15/00, G 01 N 33/18, Pat.103096 UA, bul.17, 10.19.2013.

[4] O. Vasyukov, V. Lobaychenko, V. Sabadash, "Methodical questions of research of bottled mineral waters, Theory and practice of forensic examination and criminology", Bul. Sc.Works, Kharkiv, pp.258-264, 2016.

[5] T. Bubela, P. Malachivsky, E. Pokhodylo, M. Mykyychuk, O. Vorobets, "Mathematical Modeling of Soil Acidity by Conductivity Parameters", East. Eur. J. of Entrepr. Techn., no.6/10 (84), pp.4-9, 2016. 